\begin{tabular}{|c|c|c|}
\hline $\begin{array}{l}\text { PKS } \\
\text { PUBLIC } \\
\text { KNOLLEDEG } \\
\text { PROECC }\end{array}$ & $\begin{array}{c}\text { Revista de GEOGRAFIA } \\
\text { (RECIFE) } \\
\text { http://www.revista.ufpe.br/revistageografia }\end{array}$ & 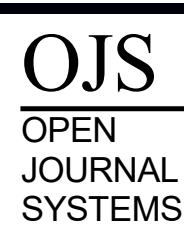 \\
\hline
\end{tabular}

\title{
CIDADANIA PAISAGÍSTICA
}

\author{
David Tavares Barbosa ${ }^{l}$ \\ ${ }^{I}$ Doutorando em Geografia na Universidade Federal do Rio de Janeiro. Email: davidtgeo@gmail.com
}

Artigo recebido em 28/08/2017 e aceito em 01/10/2017

\begin{abstract}
RESUMO
O presente artigo almeja contribuir com o debate sobre a cidadania paisagística, questão problematizada no diálogo institucional entre os grupos de pesquisa LECgeo/UFPE e GEOPPOL/UFRJ. A partir da participação nesse projeto e de algumas questões sistematizadas nos dois primeiros anos da pesquisa do doutorado em desenvolvimento, buscarei apresentar algumas proposições iniciais e articulações teóricas que permitam aproximar o debate paisagístico da pauta da justiça social e da cidadania. Nossa perspectiva de análise buscará lançar luz à possibilidade de apreender e problematizar a paisagem (e a cidadania paisagística, por extensão) enquanto um conceito e instrumento com função social, capaz de articular estratégias de contestação, resistência e canalizar ações políticas para a mobilização de direitos, construção de visibilidade social e demanda por cidadania dos grupos sociais.

Palavras-chaves: Cidadania. Paisagem. Cidadania Paisagística.
\end{abstract}

\section{LANDSCAPE CITIZENSHIP}

\begin{abstract}
This article aims to contribute to the debate about landscape citizenship, an issue discussed in the institutional dialogue between research groups LECgeo/UFPE and GEOPPOL/UFRJ. From the participation in this project and the some questions systematized in the first two years of the $\mathrm{PhD}$ research in development, I will try to present some initial propositions and theoretical articulations that allow to approach the landscape debate of the agenda of social justice and citizenship. Our perspective of analysis will seek to light on the possibility of apprehending and problematizing the current political and theoretical landscape (and the landscape citizenship, by extension), while a concept and instrument with a social function, capable of articulate strategies of contestation, resistance and political actions for the mobilization of rights, construction of social visibility and demand for citizenship of social groups.
\end{abstract}

Keywords: Citizenship. Landscape. Landscape citizenship. 


\section{CONSIDERAÇÕES INICIAIS}

No programa do V Seminário Espaço, Cultura e Política, realizado na cidade do Recife entre 07 a 11 de novembro de 2017, houve como proposta o desenvolvimento da oficina de debates nomeada como "Cidadania paisagística, patrimônio e gestão territorial”. Esse grupo de trabalho, conforme destacado no projeto do evento, assenta-se no aprofundamento de parcerias e produção de pesquisas conjuntas entre os grupos de pesquisa LECgeo/UFPE e GEOPPOL/UFRJ ${ }^{1}$. Essa parceria se faz a partir do projeto em vigência no CNPq nomeado como "Direito à Paisagem e prática da cidadania no Rio de Janeiro e Recife: Política urbana, democracia e formação de espaços políticos em metrópoles brasileiras", sob a coordenação do professor Rafael Winter Ribeiro.

A partir desse diálogo interinstitucional, já foi realizado, além do evento destacado acima, o IV Seminário LECgeo - Cidadania e Políticas da Paisagem, em setembro de 2015, na cidade do Recife, e a oficina intergrupos Política da Paisagem, em novembro de 2016, no Rio de Janeiro. Nessas atividades, as reflexões buscaram problematizar conflitos observados entre a preservação e transformação das cidades brasileiras, a partir da análise dos impactos sociais e políticos de grandes projetos urbanos. Igualmente, buscou-se apreender os agentes que mobilizam a paisagem como objeto de identidade e expressão de demandas sociais.

Ciente que as reflexões sobre a cidadania paisagística nessa rede de pesquisas ainda está em formação, gostaria de apresentar nesse artigo algumas questões sistematizadas a partir da minha participação nesse projeto interlaboratorial, assim como na pesquisa de doutorado que desenvolvo articulado a esse programa de pesquisas. A proposta de tese em andamento tem buscado apreender de que forma grupos sociais formulam e expressam suas demandas de cidadania perante a mobilização de referências paisagísticas.

Como esse texto corresponde ao primeiro exercício de sistematização sobre a questão, mais que a proposição de uma definição teórica acabada sobre a cidadania paisagística, me interessa, inicialmente, propor um diálogo crítico entre as noções de cidadania e paisagem. Neste sentido, iniciaremos nossa reflexão com um debate sobre a noção de cidadania, seguido de algumas reflexões sobre a paisagem, para, a partir de então, pensar algumas possibilidades para a formulação do novo conceito aqui apresentado.

Por fim, faz-se necessário reconhecer que cidadania e paisagem caracterizam-se como noções controversas e debatidas em diferentes disciplinas. Termos polissêmicos, antes mesmo

\footnotetext{
${ }^{1}$ Laboratório de Estudos sobre Espaço, Cultura e Política (LECgeo-UFPE) e Grupo de Estudos e Pesquisas sobre Política e Território (GEOPPOL-UFRJ). 
de conotar conceitos científicos, correspondem a noções difundidas em contextos anteriores à sistematização de diversas ciências. Com abordagens e formulações teóricas justapostas em várias disciplinas, suscitam enfoques interdisciplinares de análise, fazendo-se necessário que deixemos claro o aparato conceitual e metodológico que dá aporte às nossas análises.

Nesse sentido, há que se destacar que as reflexões que guiam este artigo encontram-se vinculadas à perspectiva de análise da geografia, em diálogo com uma leitura instrumental de alguns aportes da antropologia, com ênfases próprias ao olhar geográfico. A partir dessa ótica de análise, não iremos desenvolver aqui uma reflexão sobre a história política da instituição dos conceitos. Interessa-nos apreender como tais noções são colocadas para trabalhar na sociedade contemporânea, suas atualidades políticas e reformulações recentes.

\section{CIDADANIA: UMA IDENTIDADE SOCIAL POLITIZADA}

A noção de cidadania possibilita a construção de diferentes questões aos contextos disciplinares. Para cientistas políticos, por exemplo, debates sobre a cidadania normalmente envolvem reflexões sobre a justiça, a participação política e os direitos sociais. Antropólogos, por sua vez, podem se interessar pelos aspectos simbólicos e variações etnográficas das expressões da cidadania (PEIRANO, 2006; BOTELHO e SCHWARCZ, 2012). Geógrafos, ao seu turno, costumam refletir sobre a dinâmica territorial intrínseca ao conceito, investigando o exercício de direitos realizados nos territórios e suas conexões com o Estado (CASTRO, 2003; RIBEIRO, 2013).

Conforme destacam Botelho e Schwarcz (2012, p. 11), não há definição consensual nem análises definitivas sobre esse conceito. Observa-se uma pluralidade e instabilidade de concepções, com abordagens que "convivem e disputam significados e sentidos não só práticos como simbólicos", pois respondem à variedade de tipologias resultantes de diversas experiências históricas. Entretanto, como pondera a geógrafa Iná Castro, há um "núcleo forte do conceito", considerado como "ponto de partida filosófico" ao seu debate: a ideia que cidadania ilustra um "justo equilíbrio entre direitos e deveres na relação entre indivíduos e comunidade", que se realiza nas práticas do cotidiano social, inscritos em determinado tempo e espaço, além de ancorados no aparato institucional à disposição da sociedade no território (CASTRO, 2003, p. 08-10).

Considera-se que, por definição, cidadãos são os membros de um Estado, com direitos, deveres e status garantido de participação integral na comunidade, sendo a cidadania tanto um 
conceito como uma prática social vinculada ao exercício pleno no Estado de direitos, estando cada vez mais incorporado à gramática e experiência política cotidiana (PEIRANO, 2006; BOTELHO e SCHWARCZ, 2012; RIBEIRO, 2013). Porém, se essa acepção mais consensual da cidadania permite-nos iniciar as reflexões, ela também carrega um conjunto de impasses.

Essa acepção mínima expõe que a construção/delimitação da cidadania envolve uma dinâmica de inclusão e exclusão (criação de distinções, contrastes, status diferenciado de uma identidade cívica) entre cidadãos e não-cidadãos, podendo gerar além do convívio comum, o aumento de demandas individualistas e/ou egoísticas (BOTELHO e SCHWARCZ, 2012; PEIRANO, 2006). Assim, há de se compreender que, conforme esclarece DaMatta (1997), além do caráter jurídico-político da noção, a cidadania também comporta uma dimensão sociológica básica: é algo socialmente institucionalizado e moralmente construído.

Se a percepção dessas questões encontra-se articulada ao exercício inicial de definição do conceito, críticas contemporâneas indicam outros questionamentos ao vocábulo, com transformações profundas no seu significado, assim como nas práticas e empenhos sociais de cidadãos no cotidiano. Conforme destacam os supracitados Botelho e Schwarcz (2012), novos modelos teóricos e políticos são lançados no debate contemporâneo, transformando o conceito: outrora ligado ao pertencimento e exercício da individualidade perante um Estado nacional; agora, cada vez mais transformado em um desejo por reconhecimento político, uma vontade política expressa por diferentes grupos em declarar e defender suas diferenças.

Para estes autores, três questões centrais fundamentam a atual retomada de interesses ao debate da cidadania: i) a emergência de lutas por novos direitos, não mais exclusivos aos indivíduos, mas a grupos, etnias, nações e à própria humanidade (direito ao meio ambiente equilibrado, à paz, ao patrimônio...); ii) debate de questões relativas à pertença e identidades coletivas, reconfiguradas diante migrações e conflitos étnicos; iii) crescentes pressões sociais por justiça, que despertam a percepção de novos direitos e ampliação dos sentidos da cidadania (direito à moradia, à saúde, à educação básica, etc.) (BOTELHO e SCHWARCZ, 2012). Visto a partir dessa abordagem, podemos considerar que identidades territoriais, expressões culturais e o exercício da cidadania constituem elementos solidários e inseparáveis para a compreensão da sociedade contemporânea, indicando-nos a impossibilidade de dissociar a geograficidade dos modos culturais de suas injunções políticas (MACIEL, 2016).

O contexto brasileiro posterior a Constituição de 1988 revela-se bastante emblemático sobre esse processo de reconfiguração da cidadania. A partir desse referencial legislativo, tem-se observado nas três últimas décadas o reconhecimento da diversidade como princípio 
norteador do debate jurídico sobre as identidades e democracia (RIBEIRO, 2013). Vislumbrase a emergência de novas políticas de ação afirmativa articuladas a demandas territoriais e de reconhecimento de identidades, casos onde a proteção de práticas e espaços sociais de grupos minoritários são considerados como estratégias de reconhecimento da pluralidade da(s) identidade(s) nacional(is). Conforme destaca Ribeiro (2013) apoiado nas análises de Wilson Rocha Assis, o contexto pós-1988 permite pensar a cidadania pelo "direito à diferença", a partir da tradução de uma diversidade ontológica em pluralismo discursivo, de afirmação das diferentes expressões culturais e legitimidade de sua proteção jurídica.

Assim, o contexto contemporâneo da cidadania sinaliza uma "crescente hibridização das pautas reivindicativas", articulada ao rearranjo de valores sociais, a partir da proliferação de reivindicações, demandas por direitos e reconhecimento por diferentes grupos: deficientes, LGBTs, grupos étnicos, mulheres, movimentos urbanos, etc. (MACIEL, 2016). Tais questões, além de expor alguns questionamentos à centralidade/exclusividade de compreensão da cidadania a partir das identidades nacionais, permite-nos apreender que a cidadania tende a se construir como uma identidade social informada pela dimensão política (DAMATTA, 1997) ou, nos termos de Botelho e Schwarcz (2012), uma identidade social politizada. Conforme os termos de Botelho e Schwarcz (2012, p. 12-13):

Mas gostaríamos de voltar mais uma vez ao conceito de cidadania como “identidade social politizada”. Cidadania é noção construída coletivamente e ganha sentido nas experiências tanto sociais quanto individuais, e por isso é uma identidade social. Claro que pensamos aqui em identidade como uma construção social relativa, contrastiva e situacional. Ou seja, ela é uma resposta política a determinadas demandas e circunstâncias igualmente políticas, e é volátil como são diversas as situações de conflitos ou de agregamento social. Porque é política, também sua força ou fragilidade depende das inúmeras mobilizações, confrontos e negociações cotidianas, práticas e simbólicas. [...] "Identidade social politizada" significa, portanto, que a extensão dos direitos da cidadania democrática deve ser pensada como resultados possíveis das contendas concretas de grupos sociais, e que essas contendas são, por sua vez, fontes poderosas de identificação intersubjetiva e reconhecimento entre as pessoas. Nesse sentido, identidade e cidadania não são conceitos essenciais, fixos por natureza. Eles variam conforme a agência que fazem deles os homens que os mobilizam (BOTELHO, SCHWARCZ, 2012, p. 12-13).

A partir dessa concepção, interessa-nos destacar a dinâmica relacional da cidadania nas experiências sociais cotidianas, compreendendo-a como uma resposta política a demandas 
e circunstâncias igualmente políticas, como um exercício concreto dos direitos sobre o espaço social. Em outras palavras, falar da cidadania como uma identidade social politizada permitenos apreender que o conceito articula (além de um caráter jurídico-político-moral) modos de identificação intersubjetiva e sentimentos de pertencimento que são criados coletivamente nas mobilizações, confrontos e negociações cotidianas (práticas e simbólicas). Tais questões serão retomadas mais a frente. Por ora, passaremos agora a analisar o conceito de paisagem.

\section{PAISAGEM: ATUALIDADES POLÍTICAS E TEÓRICAS}

Antes de ser um conceito da disciplina geográfica, a paisagem corresponde a uma palavra da língua vernácula e termo técnico de outras disciplinas e práticas artísticas. Mesmo que vinculada à ideia usual de observação do meio e apreciação estética do mundo (BESSE, 2006; BERQUE, 2009), existem diversas abordagens possíveis para considerar a paisagem. Formulações teóricas justapostas em disciplinas como geografia e arquitetura, assim como concepções de paisagem vinculadas às diversas expressões artísticas e ações patrimoniais.

Alguns autores esclarecem que a paisagem nasce, enquanto noção, vinculada a um tipo específico de pintura iniciado no período da Renascença italiana, mais especificamente em Flandres (CAUQUELIN, 2007; MEINING, 2003). Conforme esclarece Cauquelin (2007, p. 81-85), a paisagem se institui ao longo de um processo histórico, a partir de uma "pedagogia da ordenação" que indica o que mostrar, como mostrar e produz uma representação e uma ideia do mundo, um conjunto entre as coisas proposto à visão. Essa formulação da paisagem a partir das artes possibilitou o estabelecimento de uma tradição da Geografia que atribui ao conceito um sentido próximo da criação estética, preocupado em evidenciar o senso dos lugares, as interinfluências entre elementos, a dimensão ontológica do observado e as influências culturais e contextuais da percepção (BARROS, 2006).

Para Berque (2009), contudo, tal concepção representa apenas a versão defendida pelo paradigma ocidental moderno, que almeja interpretar a paisagem como uma "mirada projetada no território" que anseia perceber, apreciar, explicar e atribuir uma ordem ao mundo e seus fenômenos físicos e humanos. Segundo Augustin Berque, antes da formulação ocidental, uma concepção de paisagem já se fazia presente, por exemplo, na China, a partir de uma visão cosmológica que faz nascer um sentido de paisagem a partir da relação que o indivíduo estabelece com o entorno, não apenas de olhar, mas de mediação objetiva e subjetiva com o meio (BERQUE, 2009, p. 59-64). 
O reconhecimento destas versões concorrentes, mas complementares, do 'nascimento' da noção de paisagem, antes da incorporação como conceito da Geografia, se faz necessário aqui com objetivo de reforçar o que Olivier Dollfus, ao comentar o texto da paisagem-marca, paisagem-matriz de Augustin Berque arrematou: afirmar que a paisagem, em si, se apresenta como um conceito impreciso, expressão de uma sociedade, produto cultural e histórico, mas que revela além do enquadramento da visão, uma organização territorial e uma cosmogonia (DOLFUS, 2012, p. 242-243). Entretanto, não nos interessa aqui desenvolver uma reflexão sobre a história política da paisagem ${ }^{2}$, mas apreender como esse conceito é colocado para trabalhar na sociedade contemporânea, sua atualidade política e social.

Em texto recente, o historiador Jean-Marc Besse propõe algumas interrogações sobre a paisagem no contexto contemporâneo: "O que é a paisagem nas culturas espaciais modernas e contemporâneas? Qual 'realidade' é indicada com esse nome, quais são as práticas e os valores que correspondem a esse nome, e quais são os objetos que resultam dele?" (BESSE, 2014, p. 11). Em sua perspectiva, o conceito pitoresco ou ornamental da paisagem encontrase em crise, sendo necessárias que se levantem novas perguntas, novas exigências teóricas e práticas que direcionem o debate da paisagem até a reformulação do conceito e compreensão das novas representações e práticas paisagísticas (BESSE, 2014).

Para Besse (2014), debates atuais sobre a paisagem devem considerar duas questões centrais: i) a existência de uma conjuntura teórica e historiográfica complexa sobre a noção; ii) a percepção de uma 'nova cultura da paisagem', de novas formas de experiência do espaço, da sociedade e da natureza, de novas aspirações coletivas relativas à paisagem. Ampliação da atenção atribuída à paisagem a partir de interesses políticos, econômicos e sociais diversos.

Dentre essas novas formas de experiência do espaço, Ribeiro $(2013 ; 2015)$ destaca a preocupação cada vez mais ampla que o debate da paisagem assume na construção de novos instrumentos de política urbana, presente da gestão do patrimônio cultural até ações de grupos e movimentos sociais contestatórios que reivindicam o reconhecimento de racionalidades paisagísticas. Em perspectiva próxima, Debarbieux (2007) observa uma crescente demanda paisagística contemporânea sinalizada a partir de mudança práticas, materiais e simbólicas do espaço em sociedades submetidas a profundas transformações dos territórios (coletivos e institucionais). Transformações recentes que indicam uma apropriação da paisagem como

\footnotetext{
${ }^{2}$ Definida por Besse (2014) como o estudo da instituição e construção histórica da palavra/conceito "paisagem". Além do trabalho de Jean-Marc Besse, outras análises importantes ao estudo da "história política da paisagem" podem ser consultadas em Barros (2006), Cauquelin (2007) e Meining (2003), dentre outros. 
tema importante à organização espacial, à produção de discursos sobre a cidade e prática da cidadania.

Tais transformações interferem na construção de demandas paisagísticas que invadem o debate público e transformam o assunto em tema de diversas políticas públicas. Com efeito, observa-se a ampliação do debate além das políticas convencionais que redirecionam o debate até a possibilidade de reconhecimento dos valores paisagísticos observados nas relações espaciais e práticas territoriais. Alguns autores identificam, por exemplo, o movimento de ampliação das práticas patrimoniais (RIBEIRO 2015; BRIFFAUD, 2009), a formulação do Plano Diretor do Rio de Janeiro de 2011 (RIBEIRO, 2013, 2015) e a construção e debate da Convenção Europeia da Paisagem. São diversos pontos de renovação que reforçam a paisagem como um fenômeno político e uma caixa de ressonância para temas e perguntas diversas sobre o território: patrimônio, desenvolvimento sustentável, participação, justiça, equidade, cidadania, governança, dentre outros (SGARD, 2010).

Tais questões permitem-nos compreender que o debate atual da paisagem se faz não apenas pela valoração das formas, mas principalmente pelo reconhecimento dos valores e relações espaciais, em pensar a paisagem como parte dos sujeitos que nela se reconhece e com ela estabelece uma ligação (produto e condição de sua existência) a partir de processos territoriais vinculados ao cotidiano dos sujeitos em sua relação com o mundo circundante (RIBEIRO, 2015; BRIFFAUD, 2009; BERQUE, 2009).

Nessa perspectiva, achamos necessário considerar este conceito (a paisagem e, por extensão, a cidadania paisagística) não de forma restrita ao "universo de práticas perceptivas e mentais" limitadas à esfera da arte, mas como noção que envolve um conjunto amplo de atividades paisagísticas interpretadas como uma "ação do homem em relação a seu ambiente no mundo" (BESSE, 2014). Em outras palavras, há uma ampliação do campo de objetos e práticas paisagísticas, vinculada não mais às apreensões vivenciadas pela arte, mas também, e cada vez mais, relacionada às dinâmicas do contexto social e político cotidiano, com desafios paisagísticos mais amplos. Nesse quadro de questões, passaremos agora às questões acerca da cidadania paisagística.

\section{CIDADANIA PAISAGÍSTICA: QUESTÕES PARA O DEBATE}

Nas sessões anteriores buscamos apresentar algumas questões contemporâneas sobre os conceitos de cidadania e paisagem. A partir do debate desenvolvido, interessa-nos agora 
apontar algumas questões que permitam aproximar o debate paisagístico da pauta da justiça social e da cidadania.

Conforme esclarecemos no início deste artigo, as questões aqui apresentadas estão relacionadas à pesquisa de doutorado em desenvolvimento, que tematiza algumas questões acerca da demanda por direitos e construção de visibilidade social elencada por grupos insurgentes a partir da mobilização de referências paisagísticas. Assim, vinculado à agenda de pesquisas, buscarei apresentar uma proposta de leitura do tema via perspectiva da "cidadania insurgente" apresentada por Holston (2013). A partir dessa inspiração, buscarei apreender os impactos observados com a emergência de novos atores na política urbana, sobre como esses grupos capturam conceitos e instrumentos da política urbana, produzem novos contextos e substâncias à questão e expressam novas práticas e valores da cidadania (HOLSTON, 2013).

A primeira questão que gostaríamos de apontar ao desenvolvimento das reflexões corresponde à possibilidade de aproximar o debate sobre a cidadania paisagística do contexto contemporâneo de construção da categoria de direito à paisagem. Conforme apresentado acima, há um interesse teórico, político e social crescente sobre a paisagem na sociedade contemporânea: novas experiências e instrumentos de gestão paisagística; políticas renovadas de patrimônio cultural; ações e discursos de movimentos sociais que mobilizam a paisagem como fundamento de seus questionamentos, dentre outros. Transformações que indicam uma apropriação da paisagem como tema importante para a organização espacial, produção de discursos sobre a cidade e a prática da cidadania (RIBEIRO, 2013; 2015). Conforme indica Berque (2009), tais experiências fazem da paisagem um objeto do pensamento, da ação e de argumentação social.

Articulado à construção dos novos instrumentos de gestão da paisagem, alguns debates recentes, principalmente na perspectiva do Direito e Urbanismo, tem tematizado a paisagem como um direito social essencial à qualidade de vida. Análises que consideram o direito à paisagem na perspectiva de um direito difuso da coletividade, que aporta qualidade de vida, identidade, promoção do bem-estar, conforto social e prazer estético, além de ser um recurso à atividade econômica (PRIORE, 2002; JORGE e GENTIL, 2010; ZANOLLO NETO, 2010; CUSTÓDIO, 2012; VARÓN, 2012; 2015).

Para Priore (2002), essas reflexões expressam uma aproximação da paisagem do debate jurídico internacional, admitindo a centralidade do reconhecimento da função social e política da paisagem para as populações. Do ponto de vista metodológico, tais formulações da paisagem enquanto direito difuso permitem pensar a paisagem a partir do caráter político da 
demanda de direitos e promoção de políticas públicas de valor coletivo. Como esclarecem Jorge e Gentil (2010), essa perspectiva fundamenta uma concepção da paisagem como bem coletivo contextual da sociedade que não permite se sobrepor a um direito coletivo maior, sendo necessário sua proteção (tutela legal) em respeito aos direitos da coletividade.

Também há autores que consideram a paisagem por outra perspectiva, como objeto de interesse público primário (GONÇALVES, 2015). Sem negar a possibilidade de considerar a paisagem como um direito difuso, a concepção adotada por esse autor permite estabelecer um contraponto às outras abordagens: considerar a paisagem não como um direito para um conjunto de interesses individuais unidos por circunstância conexa, mas pensar a paisagem como um interesse público referente a toda sociedade envolvida. Para esse autor, a paisagem se apresenta como um interesse público da coletividade (bem comum e indivisível) graças a sua constituição social, histórica e processual (GONÇALVES, 2015).

Compreendendo as limitações do olhar geográfico para aprofundar o debate de tais questões relativas ao direito, convém esclarecer que buscamos contribuir à questão não a partir da leitura legislativa e processual do conceito. Pensamos que, no plano da Geografia, o debate sobre tais questões podem ser exploradas, dentre outras possibilidades, a partir da análise sobre as formas como os grupos vivem em seu cadre de vie e mobilizam-no a partir dos vínculos entre suas apreciações, vivências e ligações afetivas com as paisagens cotidianas (BRIFFAUD, 2009; CUSTÓDIO, 2012).

Conforme exposto por Botelho e Schwarcz (2012), o contexto contemporâneo tem direcionado a apreensão da cidadania para além de um conceito, mas como um desejo, como um instrumento manejado pelos grupos para demandar reconhecimento político e afirmar suas diferenças sociais e identitárias. Em perspectiva próxima, Holston (2013, p. 13) destaca que, no contexto brasileiro, cidadania tem se tornado cada vez mais uma palavra ubíqua e com uso evocativo à futuros alternativos, passando de algo estático e alienante, para algo insurgente e indispensável, muito embora arriscado e deficiente.

Igualmente, no debate paisagístico contemporâneo podemos observar a formulação de discursos e ações que articulam demandas de reconhecimento social à valoração de horizontes paisagísticos. Ações que atribuem um papel central à paisagem nas lutas por direitos, a partir da expressão daquilo que gostaríamos de nomear como vontades de paisagem, como um desejo crescente, expresso por grupos diversos, de se sentirem representados nos horizontes 
paisagísticos, de ter seu estar no mundo, suas marcas territoriais e expressões simbólicas reconhecidas e valoradas ${ }^{3}$.

Devido ao reduzido espaço desse artigo, não conseguiremos problematizar alguns exemplos atuais que expressam essas vontades de paisagem. Entretanto, já apresentamos e debatemos algumas dessas questões em trabalhos anteriores, a partir da análise do movimento \#OcupeEstelita e do imbróglio público acerca da tentativa de construção do empreendimento imobiliário Novo Recife ${ }^{4}$ (BARBOSA, 2014; 2017). Neste sentido, um caso específico sobre a atualidade política expressa por vontades de paisagem tem estimulado nossa pesquisa: ações desenvolvidas por grupos sociais insurgentes no estuário sul da cidade do Recife.

Esse ambiente de estuário localiza-se na planície sedimentar do Recife, entre o centro histórico-geográfico e a zona sul da cidade, onde termina o percurso comum de diversos rios que cortam o Recife: Tejipió, Jordão, Pina e o braço sul do Capibaribe. Na atualidade, corresponde a uma dos espaços mais dinâmicos do cenário urbano recifense, sendo, antes de tudo, um espaço de importância ecológica, política, mas também histórica e cultural à cidade.

Vinculado a um contexto contemporâneo de grandes transformações urbanas, com a implantação de grandes empreendimentos imobiliários, viários e comerciais, e entre duas áreas dinâmicas da cidade ( $\mathrm{O}$ Centro e a Zona Sul), observa-se também neste espaço a ampliação de práticas insurgentes para discutir o fato urbano do Recife. Grupos que, a partir de uma metodologia de atuação variada, organizam ações, constroem demandas políticas e mobilizam espaços políticos diversos com objetivos de fortalecer identidades, romper com

\footnotetext{
${ }^{3}$ A proposição da ideia de "vontades de paisagens" toma como ponto de partida o debate de Pierre Nora sobre a constituição da "vontade de memória". Para este autor, a vontade de memória é um dos aspectos centrais da constituição dos lugares de memória. Se para este autor, lugares de memória são "sinais de reconhecimento e de pertencimento de grupo numa sociedade" (NORA, 1993, p. 12-13), estes se formulam a partir de uma "vontade geral de registro", da vontade de encontrar origens, de criar sinais de reconhecimento e pertencimento de grupos sociais no processo da história (NORA, 1993, p. 12-17). A partir de sua formulação, construímos a ideia de "vontade de paisagem" como o desejo expresso por diferentes grupos de se sentir representado nos horizontes paisagísticos, de ter seu "estar no mundo", suas marcas territoriais e expressões simbólicas reconhecidas e valoradas.

${ }^{4}$ O Projeto Novo Recife corresponde a um projeto de reconfiguração do Cais José Estelita, amplo terreno localizado entre o centro histórico-geográfico e a zona sul do Recife. Pensado inicialmente como expansão do Porto do Recife e aterrado para abrigo de galpões de armazenamento, passou a integrar também o Pátio Ferroviário das Cinco Pontas. Atualmente, neste espaço existe um conjunto de equipamentos e instalações portuárias e ferroviárias, tais como galpões, armazéns, etc. Atualmente, o terreno é o centro da polêmica em torno do projeto de reconfiguração nomeado como "Novo Recife", onde um grupo de construtoras propõe transformar o espaço a partir da construção de um conjunto de grandes edifícios residenciais, empresariais e hotéis, além de um conjunto de obras viárias. Perante esses processos de renovação urbana, o Ocupe Estelita emergiu como um grupo de pressão que a partir de ações de ocupação de espaços públicos, uso do meio audiovisual para contestação, produção de debates e eventos, dentre outras metodologias, contribuem para a promoção de discussões ampliadas sobre o acirramento da questão urbana do Recife. Mais que um grupo coeso, há um coletivo aberto e autônomo de cidadãos e grupos articulados com o objetivo de discutir os problemas da cidade, mas também propor novas ideias e rumos ao planejamento. 
estereótipos locais, possibilitar a permanência de grupos em seu território e reivindicar o reconhecimento de paisagens desse estuário como expressão de suas demandas cidadãs.

São grupos de cidadãos comuns, moradores locais e grupos de pesquisadores que tem organizado estratégias para contestar projetos de intervenção urbana e utilizam de debates e ações sobre/na paisagem para justificar e legitimar suas reivindicações. Mobilizações que buscam o reconhecimento das paisagens do Estelita como um "horizonte nostálgico" com valor histórico à cidade, às pessoas e suas diferentes territorialidades, quer dizer, como um direito coletivo e legítimo a todos os cidadãos do Recife ${ }^{5}$. Pedidos de tombamento da memória ferroviária e paisagem cultural do Pátio Ferroviário das Cinco Pontas (Figura 01), encaminhadas ao IPHAN e MPF, dentre outros.

Figura 01 - Ocupe Estelita: Paisagem, memória e direito à paisagem

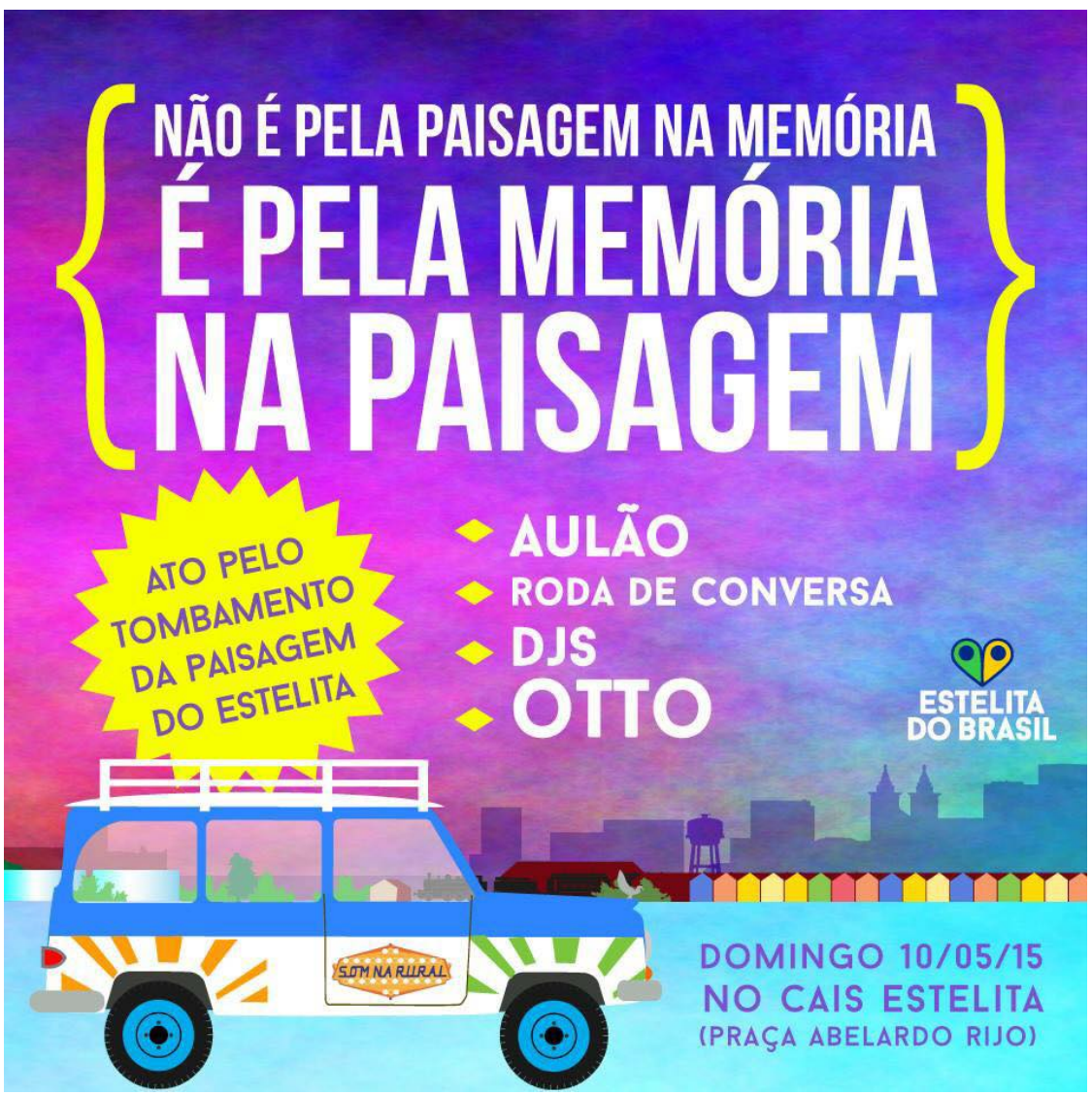

FONTE: https://www.facebook.com/EstelitaDoBrasil.

\footnotetext{
${ }^{5}$ Questões expostas no documento "Nosso Recife. Conceitos e metodologias para um planejamento cidadão: repensando o Cais José Estelita", entregue à Prefeitura do Recife e produzido por professores do curso de Arquitetura e Urbanismo da Universidade Católica de Pernambuco como contraponto à proposta de intervenção do Novo Recife. Reflexões também destacadas, por exemplo, na tese "Paisagem-postal: A imagem e a palavra na compreensão de um Recife urbano", de Lúcia Maria de Siqueira Cavalcanti Veras, do Programa de PósGraduação em Desenvolvimento Urbano da UFPE. 
Assim, identificamos no estuário sul recifense diversas ações sociais que expressam demandas de direito às paisagens segundo diferentes expressões: desejo por reconhecimento dos valores patrimoniais de certos panoramas históricos da cidade; apelo para ter saberesfazeres e práticas paisagísticas históricas legitimadas e incorporadas às retóricas paisagísticas oficiais, dentre outros. Questões que possibilitam pensar a paisagem como objeto de disputa, expressão de processos de resistência e construção de visibilidade social, e permite-nos apreender uma dinâmica política expressa a partir de lutas na, pela e a partir da paisagem. Tal dinâmica de práticas e discursos políticos insurgentes foi a que nos estimulou a pensar sobre a geografia política que está por trás disso.

Conforme demonstra (CASTRO, 2002), os indivíduos expressam suas motivações paisagísticas a partir dos olhares construídos, das heranças culturais e experiências individuais e coletivas que vivenciam. Assim, consideramos que as vontades de paisagem articulam os sentidos do meio às marcas territoriais e expressões simbólicas, sendo mobilizadas no contexto social enquanto estratégia para criar coerência e marcos referenciais, articuladas às narrativas históricas de suas territorialidades. Vontades de paisagem expressas por "novas formas de investimento de si no espaço público" que associam desejos de "ter" e "narrar" suas histórias com a (re)produção de novos instrumentos de validação e reconhecimento social (MOTA, 2014, p. 135-140).

Assim, o contexto contemporâneo permite observar uma interconexão entre o debate teórico da cidadania e da paisagem: tais conceitos são tomados como importantes vocábulos na luta por reconhecimento (social, cultural, político e jurídico) e pertencimento dos grupos na sociedade. Nessa luta, tais conceitos assumem um papel central na construção de novas estratégias de investimento de si no espaço público, na articulação entre os desejos e a produção de novos instrumentos de reconhecimento social.

Neste sentido, vislumbramos como possibilidade à análise geográfica problematizar como diferentes grupos constroem e articulam suas vontades de paisagem às estratégias de reconhecimento de suas cidadanias, sendo a paisagem o objeto de disputa (um direito), mas também o dispositivo que canaliza outras lutas políticas (um instrumento político). Nessa perspectiva, pensamos ser importante à geografia se aproximar do debate sobre o direito à paisagem $^{6}$ : problematizar os direitos subjetivos que cada um dispõe sobre a paisagem do qual

\footnotetext{
${ }^{6}$ Uma das publicações mais influentes sobre a questão, amplamente citada por diversos textos, corresponde às reflexões do jurista do Conselho da Europa Riccardo Priore. Esse autor realiza uma distinção entre o "direito de paisagem" e o "direito à paisagem": Direito de paisagem pode ser considerado como um domínio autônomo do direito e um subdomínio do direito ambiental, quer dizer, o quadro jurídico onde se aplicam normas de proteção 
se encontra próximo, buscando analisar os processos de instrumentalização política do conceito, apoiado em atos conscientes de atribuição de valor com interesses políticos e sociais. Em outras palavras, buscar refletir sobre como a paisagem - não tanto o conceito, mas a articulação desta noção com o imaginário geográfico - se articula com os processos de recomposição das identidades, estratégias de autorreferência e usos políticos do conceito como documento de reivindicação e organização de lutas.

Para Debarbieux (2007) essas preocupações paisagísticas contemporâneas ilustram um contexto teórico que permite apreender a "paisagem-como-ação" ("paysage-comme-action"), 'ação' aqui compreendido conforme o significado atribuído por Hannah Arendt: fonte de definição da identidade política do sujeito e modalidade pela qual os homens em sociedade definem o que tem em comum e o colocam no coração do espaço público. Paisagem que se apresenta como uma oportunidade ao "vivre ensemble dans le monde", como possibilidade de construção de um comum.

Com efeito, essa perspectiva também é defendida, por exemplo, por Serge Briffaud, que destaca a necessidade de compreender a paisagem como sinônimo de cadre de vie, problematizando-a a partir do olhar do habitante, das subjetividades, valores e sentimentos compartilhados (BRIFFAUD, 2009). Para este autor, o contexto contemporâneo indica-nos a necessidade de problematizar o potencial de representação social das paisagens, suas percepções socioculturais, experiências vividas e uso dos territórios correlatos. Segundo os termos deste autor:

Le paysage, ici, n'est plus d'abord ce qui existe par la mediation de l'oeuvre d'art, mais plutôt par celle du regard de l'habitant, qui projete sur l'espace des valeurs et des sentiments dont la prise en compte doit fonder les politiques en ce domaine. Ce paysage replacé au carrefour des subjectivités est le contraire d'un site-tableau, dont on peut décréter la valeur. Il n'est plus seulement évaluable en termes esthétiques, mais en termes de representation sociale, c'est-à-dire relativement à des perceptions qui s'enracinent dans des substrats culturels socialement différenciés et qui ne peuvent être séparés du vécu et de l'usage fait des territoires. Ce paysage-là n'est plus pittoresque. Il n'est plus ce que regarde, de loin et en passant, un observateurvoyager, mais ce qui est contemplé de l'intérieur par um habitant-acteur, reconnu non seulement comme détenteur d'um regard de référence, mais aussi pour sa

às "situações jurídicas subjetivas" (interesses particulares sobre a paisagem). O direito à paisagem, mas que uma construção teórica, corresponde ao próprio interesse paisagístico, ao ato de reconhecimento individual e coletivo dos cidadãos de pertencimento a uma sociedade determinada (PRIORE, 2002). É dessa segunda concepção que buscamos dialogar a partir da perspectiva geográfica. 
participation à la production et à l'entetien des formes perceptibles ${ }^{7}$ (BRIFFAUD, 2009, p. 46).

Pensar a paisagem em termos dos hábitos, das atividades sociais, das ações cotidianas nos estimula a pensar o debate não a partir de um objeto acabado, mas como algo sempre sujeito às circunstâncias sociais, culturais, econômicas e negociações dos indivíduos e coletivos sociais no presente. Aqui, observamos um desafio: compreender a paisagem como expressão dessas questões íntimas com os territórios particulares revela também a necessidade de considera-la na perspectiva do espaço público, como espaço da ação, de visibilidade, encontros, controversas e pluralidade de perspectivas. Quer dizer, reflexão sobre o caráter democrático de sua dinâmica social (SGARD, 2010). Aqui, as conexões com a abordagem de cidadania como identidade social politizada são claras e reforçam a validade da questão.

A partir dessas questões, dentro de uma conjuntura teórica que permite-nos pensar a paisagem enquanto uma ação (política, social e intersubjetiva) e fonte de definição da identidade política dos grupos sociais, gostaríamos de finalizar esse artigo com algumas indicações para a abordagem sobre a cidadania paisagística. Primeiro, precisamos retomar o debate sobre a paisagem (enquanto conceito e cenário de visibilização da vida e da diferença) como uma construção coletiva da sociedade, reafirmando sua função social e fortalecendo os valores democráticos que norteiam as ações individuais e do planejamento da cidade.

Entretanto, uma perspectiva mais inclusiva da paisagem não deve se fazer a partir de uma moral fundada em aceitar novas práticas paisagísticas, baseadas simplesmente na simpatia e tolerância, mas sim a partir da reflexão sobre os valores paisagísticos, sua gestão e distintas instrumentalizações na produção dos discursos e ações (RIBEIRO, 2013; SGARD, 2010). É preciso ir além da questão de reconhecimento/atribuição das identidades e pensar questões práticas ao exercício da cidadania paisagística. Se o reconhecimento das identidades culturais é um pressuposto indispensável do cidadão, o acesso/participação na apropriação e seleção dos valores também devem ser considerados (RIBEIRO, 2013).

\footnotetext{
${ }^{7}$ LIVRE TRADUÇÃO: “A paisagem, aqui, não é mais o que existe pela mediação da obra de arte, mas antes por aquele olhar do habitante, que projeta sobre o espaço os valores e os sentimentos considerados fundadores políticos em seu domínio. Essa paisagem que recupera o cruzamento das subjetividades é o contrário de um sítio-quadro, onde pode-se decretar valor. Ele não é mais somente avaliado em termos estéticos, mas em termos de representação social, quer dizer, relativamente às percepções que se enraízam nos substratos culturais socialmente diferenciados e que não podem ser separados do vivido e do uso feito nos territórios. Essa paisagem não é mais pitoresca. Ela não é mais o que se observa, de longe e de passagem, por um observador-viajante, mais o que é comtemplado do interior, por um habitante-ator, reconhecido não simplesmente como detentor de um olhar de referência, mas também por sua participação na produção e conservação das formas perceptíveis". 
Segundo, podemos usar a categoria cidadania paisagística como estratégia teóricometodológica, mas também política, que permita compreender como as mobilizações cidadãs se constroem a partir das relações dos grupos com seus quadros de vida, suas paisagens (DEBARBIEUX, 2007; BOTELHO e SCHWARCZ, 2012; BERQUE, 2009). Em outras palavras, é preciso problematizar a dimensão "sociopolítica" de mobilização da paisagem: as relações que os homens mantém entre si a partir da paisagem, sua valorização socialmente produzida, seus interesses e práticas diferenciadas, as demandas sociais crescentes sobre o usufruto da dimensão paisagística dos territórios.

Em nossa compreensão, tais postulados reforçam a proposição da "leitura heterotópica da paisagem" exposta por Paul Claval, que destaca a necessidade de considerar a paisagem como o lugar do outro, para destacar suas descontinuidades, dissonâncias e rupturas como consequência das ontologias diferenciadas dos lugares (CLAVAL, 1994, p. 64-67). Questões que colocam em jogo novos valores e novas sensibilidades que ultrapassam o exercício da arte e interrogam, de forma mais ampla, as relações com o real, com os "quadros perceptivos e simbólicos da experiência do mundo" (BESSE, 2014, p. 23-24).

Tais questões possibilitam o debate da paisagem como objeto de disputa, expressão de processos de resistência e construção de visibilidade social. Tal como demonstra Besse (2014, p. 26), pensar a paisagem a partir de sua vertente política exige considerar a dimensão de objetividade prática expressa na/pela paisagem, nas formas de habitar o espaço, nos sistemas de ideias e representações e suas experimentações correlatas. Tal concepção, mais que uma construção teórica, apresenta vínculos com demandas insurgentes de populações diversas que demandam reconhecimento aos seus marcos/marcas cotidianos de vida. As paisagens, a partir de seu intrínseco potencial político, assumem o papel de mediatizar de maneira sensível a relação estabelecida entre sujeitos e o espaço, a partir dos imaginários paisagísticos, discursos e seus processos de negociação social (BARBOSA, 2014).

Esse debate sobre a paisagem envolve pensar espaços de vida, realidades imediatas e futuras da cidade, palcos da existência de sujeitos sociais múltiplos. Conforme demonstra Sgard (2010), a paisagem corresponde a um objeto político com horizonte ético, cuja abordagem geográfica deve compreender como se tramam e se dizem as diferentes relações entre os habitantes e seus territórios, em todas as escalas. Quer dizer, apreender a paisagem como um fenômeno político que coloca em perspectiva o diálogo constante entre a pluralidade de formas de "se dizer" e "se fazer" a paisagem no "vivre-ensemble". 
Em diálogo com a proposta teórico-metodológica debatida, achamos necessário e possível aproximar a abordagem da paisagem das reflexões sobre a democracia e exercício da cidadania, buscando apreender como racionalidades paisagísticas participam da ação política de grupos sociais em suas reivindicações por direitos e engajamento de suas cidadanias. Tais questões são essenciais às preocupações das abordagens cultural e política da geografia, da geografia social enfim, visto que possibilita compreender como a paisagem articula, a um só modo, pensamentos, ações e negociações necessárias à manutenção da sociedade democrática.

\section{CONSIDERAÇÕES FINAIS}

Com este artigo, buscamos apresentar novas possibilidades para pensar a paisagem numa perspectiva inclusiva, considerando-a como possibilidade de expressão da cidadania. Tal debate torna-se central à sociedade contemporânea, visto que reconhecer direitos a partir da paisagem pode valorizar o reconhecimento de identidades, pressuposto indispensável da qualidade do cidadão, garantindo à sociedade a participação na seleção e/ou definição dos valores paisagísticos locais.

Eis então o ponto geográfico do debate que buscamos desenvolver: justificar a pertinência do debate da cidadania paisagística a partir da valorização das práticas e relações particulares dos grupos com seus espaços. Questionar como os saberes-fazeres cotidianos e os anseios paisagísticos podem ser o ponto de partida para ensejar questões relativas ao direito à paisagem. Ancorado nessa concepção, acreditamos na possibilidade de pensar a cidadania paisagística como um efeito de validação e reconhecimento de diferentes formas de viver o espaço, cujas demandas práticas de cidadania podem estar articuladas às práticas urbanísticas, aos atos culturais de construção de suas paisagens circundantes.

Por fim, queremos admitir que ao propor essas reflexões, almejamos indicar à disciplina geográfica a necessidade de observar e reconhecer a diversidade de formas de vivência das paisagens. Buscamos apresentar novas possibilidades de trabalhar o conceito de paisagem numa concepção integradora de exposição da diversidade dos espaços, dos modos de viver e querer viver este espaço. Aprimorar estratégias que mostrem a polifonia que emana dos espaços é possibilitar o direitos aos diferentes grupos que estão co-presentes nos espaços de que todos sejam paisagem, e estejam em suas representações. 


\section{REFERÊNCIAS}

BARBOSA, David Tavares. Novos Recifes, Velhos Negócios. Política da paisagem no processo contemporâneo de transformações da bacia do Pina - Recife/PE: Uma análise do Projeto Novo Recife. 2014. Dissertação (Mestrado em Geografia) - Universidade Federal de Pernambuco, Recife.

- Ocupe Estelita: Das tramas insurgentes à mobilização de direitos na política urbana. In: XII ENANPEGE, 2017, Anais... Porto Alegre: 2017, 12p.

BARROS, Nilson Cortez Crócia de. Quatro Comentários sobre Paisagem e Região. In: SÁ, A. J. de; CORRÊA, A. C. de B. (Org.). Regionalização e Análise Regional: Perspectivas e abordagens contemporâneas. Recife: EdUFPE, 2006, p. 23-31.

BERQUE, Augustin. El Pensamiento Paisajero. Madrid: Biblioteca Nueva, 2009.

BESSE, Jean-Marc. Ver a Terra: Seis ensaios sobre a paisagem e a geografia. São Paulo: Perspectiva, 2006.

. O Gosto do Mundo: Exercícios de paisagem. Rio de Janeiro: EdUERJ, 2014.

BOTELHO, André; SCHWARCZ, Lilia Moritz. Introdução - Cidadania e direitos: aproximações e relações. In: BOTELHO, A.; SCHWARCZ, L. M. (Org.). Cidadania, um projeto em construção: Minorias, justiça e direitos. São Paulo: Claro Engima, 2012, p. 0627.

BRIFFAUD, Serge. La Culture du Pittoresque et le Patrimoine Paysager Contemporain. In: Patrimoine et Paysages. Lyon: Lieux Dits, 2009, p. 40-47.

CASTRO, Iná Elias de. Paisagem e Turismo: de estética, nostalgia e política. In: YÁZIGI, Eduardo. (Org.). Turismo e Paisagem. São Paulo: Ed. Contexto, 2002, p. 121-140. . Instituições e território. Possibilidades e limites ao exercício da cidadania. GeoSul. Florianopólis, v. 18, no 36, jul./dez. 2003, p. 07-28. Disponível em: <https://periodicos.ufsc. br/index.php/geosul/article/view/13575>. Acesso em 10 ago. 2017.

CAUQUELIN, Anne. A Invenção da Paisagem. São Paulo: Martins, 2007.

CLAVAL, Paul. L'analyse des paysages. Géographie et Cultures, Spécial Paysage. Printemps 1994, no 13, p. 55-74.

CUSTÓDIO. Maraluce Maria. Conceito Jurídico de Paisagem. 2012. Tese (Doutorado em Geografia) - Programa de Pós-Graduação em Geografia, UFMG, Belo Horizonte, 2012. 
DAMATTA, Roberto. Cidadania: A questão da cidadania num universo relacional. In: DAMATTA, R. A casa e a rua: Espaço, cidadania, mulher e morte no Brasil. Rio de Janeiro: Rocco, 1997, p. 65-95.

DEBARBIEUX, Bernard. Actualité Politique du Paysage. Revue de Géographie Alpine | Journal of Alpine Research: 2007, nº 95-4.

DOLLFUS, Olivier. A produção do meio (Comentário a "Paisagem-Marca, PaisagemMatriz: elementos da problemática para uma Geografia Cultural” de Augustin Berque). In: CORRÊA, R. L.; ROSENDAHL, Z. (Org.) Geografia Cultural: Uma antologia. Rio de Janeiro: EdUERJ, 2012, p. 239-243.

GONÇALVES, Fábio Christiano Cavalcanti. A paisagem como fenômeno e objeto de interesse público: com que direito? Desenvolvimento e Meio Ambiente, v. 34, ago. 2015, p. 99-116. Disponível em: < http://ojs.c3sl.ufpr.br/ojs/index.php/made/article/view/39224>. Acesso em: 13 maio de 2016.

HOLSTON, James. Cidadania Insurgente: Disjunções da democracia e da modernidade no Brasil. São Paulo: Companhia das Letras, 2013.

JORGE, Ana Paula; GENTIL, Plínio Antônio Britto. Tutela Jurídica da Paisagem Urbana: Rumo à defesa do direito à qualidade de vida. In: XVIII Congresso Nacional do CONPEDI, 2009, Anais... São Paulo: 2009, p. 2996-3013. Disponível em: <http://www.publicadireito. com.br/conpedi/manaus/arquivos/anais/sao_paulo/2623.pdf>. Acesso em 12 maio de 2016.

MACIEL, Caio Augusto Amorim. Cultura e Política em Diálogo na Geografia Humana: Comentário sobre as possibilidades de se pensar os espaços da interculturalidade. Revista GeoSertões, $n^{\circ}$ 01, vol. 01, jan./jul. 2016. Disponível em: <http://revistas.ufcg.edu.br/cfp/ index.php/geosertoes/index>. Acesso em 18 out. 2016.

MEINING, Donald W. O Olho que Observa: Dez versões da mesma cena. Espaço e Cultura, $\mathrm{n}^{\mathrm{o}}$ 16, jul./dez. 2003, p. 35-46. Disponível em: <http://www.e-publicacoes.uerj.br/index.php/ espacoecultura/article/view/7424/5380>. Acesso em: 17 abr. 2015.

MOTA, Fábio Reis. Cidadãos em toda parte ou cidadãos à parte? Demandas de direitos e reconhecimento no Brasil e na França. Rio de Janeiro: Consequência, 2014.

NORA, Pierre. Entre Memória e História: A problemática dos lugares. Projeto História: Revista do Programa de Estudos Pós-Graduados em História e do Departamento de História da PUC-SP, n. 10. São Paulo, dez. 1993, p. 07-28. Disponível em: <http://revistas.pucsp.br/ index.php/revph/article/view/12101>. Acesso em 22 dez. 2016. 
PEIRANO, Mariza. A Teoria Vivida: e outros ensaios de antropologia. Rio de Janeiro: Jorge Zahar Ed., 2006.

PRIORE, Riccardo. Derecho al Paisaje, Derecho del Paisaje. In: NARANJO, Florencio Zoido; MORENO, Carmen Venegas (Coord). Paisaje y ordenación del território. Junta de Andalucía: Sevilla, 2002, p. 92-99.

RIBEIRO, Rafael Winter. Paisagem, Patrimônio e Democracia: Novos desafios para políticas públicas. In: CASTRO, I. E. de; RODRIGUES, J. N; RIBEIRO, R. W. (Org.). Espaços da Democracia: Para a agenda da Geografia Política contemporânea. Rio de Janeiro: Bertrand Brasil, 2013, p. 235-259.

- Paisagem Cultural Urbana e Paisagem Histórica Urbana: O Rio de Janeiro e os desafios recentes para a lista do patrimônio mundial. Identidades: Território, Projeto, Patrimônio. Vol. 06, 2015, p. 235-256.

ROUSSO, Anny. Le droit du paysage: un nouveau droit pour une nouvelle politique. Courrier de l'environnement de l'INRA, n²6, p. 29-42. Disponível em: <http://www7.inra. fr/lecourrier/assets/C26Rousso.pdf>. Acesso em: 05 nov. 2016.

SGARD, Anne. Une «éthique du paysage» est-elle souhaitable?. VertigO. Vol. 10, nº 01, avril 2010. Disponível em: <http://vertigo.revues.org/9472>. Acesso em 03 mai 2016.

VARÓN, Diana Carolina Zuluaga. El paisaje: ¿un interés juridicamente relevante? Revista Digital de Derecho Administrativo. No 08, segundo semestre 2012, p. 69-87. Disponível em: $<$ http://revistas.uexternado.edu.co/index.php/Deradm/article/view/3384>. Acesso em: 31 mai 2016.

El derecho al paisaje en Colombia: Consideraciones para la definición de su contenido, alcance y límites. Bogotá: U. Externado de Colômbia, 2015.

ZANOLLO NETO, Antônio. Direito à paisagem. Revista Internacional de Direito e Cidadania, n. 8, p. 29-37, outubro/2010. Disponível em: < http://www.reid.org.br/ arquivos/00000202-03-antonio_zanollo.pdf>. Acesso em 12 maio de 2016. 